\title{
Epithelial Dysplasia in Oral Mucosa and its Association with Betel Quid Chewing
}

\section{Waris $\mathbf{S}^{*}$ and Nagi AH}

Department of Morbid Anatomy and Histopathology, University of Health Sciences, Lahore, Pakistan

*Corresponding author: Waris S, Department of Morbid Anatomy and Histopathology, University of Health Sciences, Lahore, Pakistan, Tel: +92333912745; E-mail: dr.sadafwaris@yahoo.com

Rec date: Jun 13, 2014, Acc date: Jun 21, 2014, Pub date: Jun 23, 2014

Copyright: (C) 2014 Waris S, et al. This is an open-access article distributed under the terms of the Creative Commons Attribution License, which permits unrestricted use, distribution, and reproduction in any medium, provided the original author and source are credited.

\begin{abstract}
Objectives: Current study was performed to determine the frequency of epithelial dysplasia in pan chewers and to calculate association between the quantity and quality of pan chewing and epithelial dysplasia and its grades.

Methods: This was a cross-sectional, analytical study. Cytological smears from 300 subjects were collected. After fixation with alcohol, smears were then air dried and stained with Haematoxylin and Eosin, Giemsa and Pap's stain. The material was then examined under an optical microscope. Epithelial dysplasia was identified and graded using the method of Speight.
\end{abstract}

Results: Epithelial dysplasia was observed in $57.7 \%$ of the habitual pan chewers which was significantly associated with number of pans consumed per day as well as duration of pan consumption. These were variables were positively correlated with grading of epithelial dysplasia.

Conclusions: The study concludes that epithelial dysplasia was common among chronic pan chewers in Lahore city. Significant association and correlation was found between epithelial dysplasia and number of pans consumed per day as well as duration of pan consumption.

Keywords: Betel quid; Oral mucosa; Epithelial dysplasia

\section{Introduction}

Pan, also called Betel quid, consists of the betel leaf from the Piper betle, with a mixture of areca nut, and slaked lime (calcium hydroxide) [1]. In Pakistan, pan is made by smearing a betel leaf with slaked lime (choona), catechu paste (katha), chopped areca nut, a variety of condiments, with or without sweetners and flavours [2]. Approximately 600 million people around the world use areca nut as a masticatory substance and according to an estimate about $10-20 \%$ of the world's population chew areca nut in some form, often mixed in betel quid (pan) [3].

Reactive oxygen species (ROS) are produced in substantial amounts in oral cavity during chewing of betel quid/ betel nut [4]. These ROS are detrimental to the oral mucosa as they are reported to be directly involved in initiating the tumorigenesis, either by inducing mutations, or by making the oral mucosa vulnerable to environmental toxicants [5]. Areca nut and betel quid, without tobacco, have been declared by International Association for Research on Cancer (IARC) as Group 1 carcinogens to humans and a cause of oral cancer [6].

The morphological forerunner of an oral cancer is epithelial dysplasia which is defined as "a pre-cancerous lesion of stratified squamous epithelium characterized by cellular atypia and loss of normal maturation and stratification short of carcinoma in situ" [7]. There is no specific clinical appearance for oral epithelial dysplasia but lesions such as leukoplakia and erythroplakia are associated with dysplastic changes [8]. Therefore, only cytological examination can reveal the epithelial dysplasia and predict the future oral cancer in high risk populations [9]. Current study was performed to determine the frequency of epithelial dysplasia in pan chewers and to calculate association between the quantity and quality of pan chewing and epithelial dysplasia and its grades.

\section{Materials and Methods}

This was a cross-sectional, analytical study. It was conducted in the department of Morbid Anatomy and Histopathology at the University of Health Sciences, Lahore during April 2011 and December 2012 after approval of Ethics Review Committee of the institution. Cytological smears from 300 subjects were collected from Punjab Dental Hospital; Mayo hospital Lahore and different pan shops within Lahore city. The samples were collected from subjects on basis of non-probability convenience sampling, due to their convenient accessibility and proximity to the researcher. Chronic pan chewers of all ages ( 5 or $>5$ years duration) and both genders were included in the study after their written consent. Occasional pan chewers and inadequate smears were excluded. Socio-demographic information (name, age, sex, full address, history of other risky habits, average number of pan consumption/day and type of pan etc) was obtained along with relevant clinical details. For the purpose of categorizing, 1-5 pan consumed per day was taken as 'light', 6-10 pan consumed per day was considered 'moderate' and more than 10 pan consumed per day was taken as 'heavy' pan chewing. All the information was collected on a specially designed proforma and recorded.

Before taking smears, every subject was asked to rinse the oral cavity. Scrapings were then taken from oral mucosa with a wooden spatula and carefully transferred onto a glass slide for fixation. The 
Citation: Waris S, Nagi AH (2014) Epithelial Dysplasia in Oral Mucosa and its Association with Betel Quid Chewing. J Cytol Histol 5: 258. doi:

Page 2 of 4

contents of the slide were fixed by keeping the slide in a fixative solution for 30 seconds. 100 millimeters fixative solution consisted of 30 parts of ether into 70 parts of ethyl alcohol. After fixation, slides were then air dried. All the slides were stained with Haematoxylin and Eosin, Giemsa and Pap's stain. The material was then examined under an optical microscope. Epithelial dysplasia was identified and graded using the method mentioned by Speight et al. [10].

\section{Results}

In this study, 300 betel quid chewers having mean age $32.28 \pm 0.59$ (Range: 17-70) years and male to female ratio 19:1 were included. Epithelial dysplasia was ascertained on the basis of cytomorphological features as mentioned in Materials and Methods. Oral epithelial dysplasia was observed in $57.7 \%$ of the habitual pan chewers. Mild dysplasia was found in $22 \%$ cases as shown in Figure 1 . Moderate dysplasia was found in $25 \%$ cases as shown in Figure 2. Severe or high grade dysplasia was found in $11 \%$ of cases as shown in Figure 3. The subjects who were diagnosed to have epithelial dysplasia were compared with those who were diagnosed to have no epithelial dysplasia in terms of quantitative and qualitative parameters pertaining to betel quid.

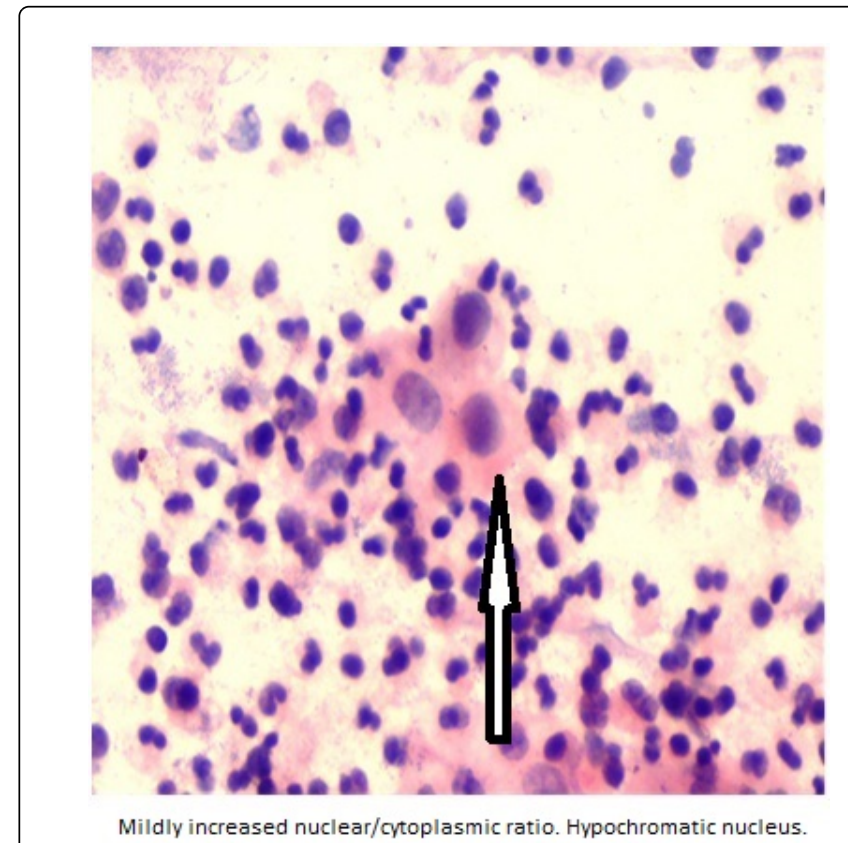

Figure 1: Mildly increased nuclear/cytoplasmic ratio. Hyochromatic nucleus.

The quantity of 'pan' consumption was ascertained by the number of 'pan' consumed per day and total duration of 'pan' abuse. Quality of pan consumed was assessed whether the 'pan' contained tobacco or otherwise. To check these associations, null hypothesis (H0) used was 'there is no association between pan consumed per day, duration of pan consumption, tobacco containing versus tobacco free pan and development of epithelial dysplasia'. If the association between these three parameters with epithelial dysplasia was found significant, it was further analysed to see their association and correlation with the cytological grades of dysplasia.

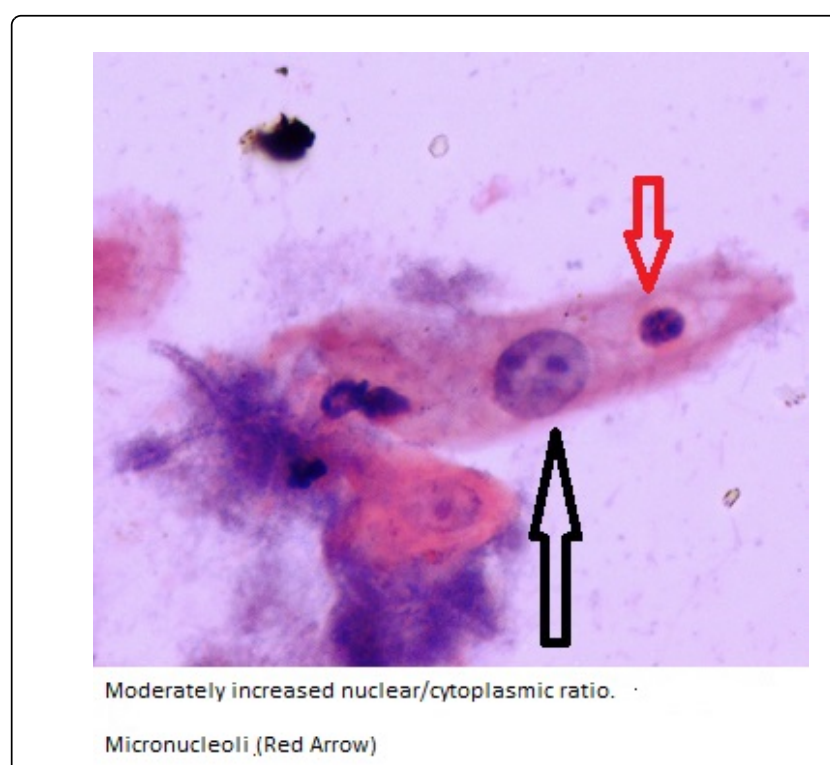

Figure 2: Moderately increase nucleae/cytoplasmic ratio. Micronuclei (Red Arrow.)

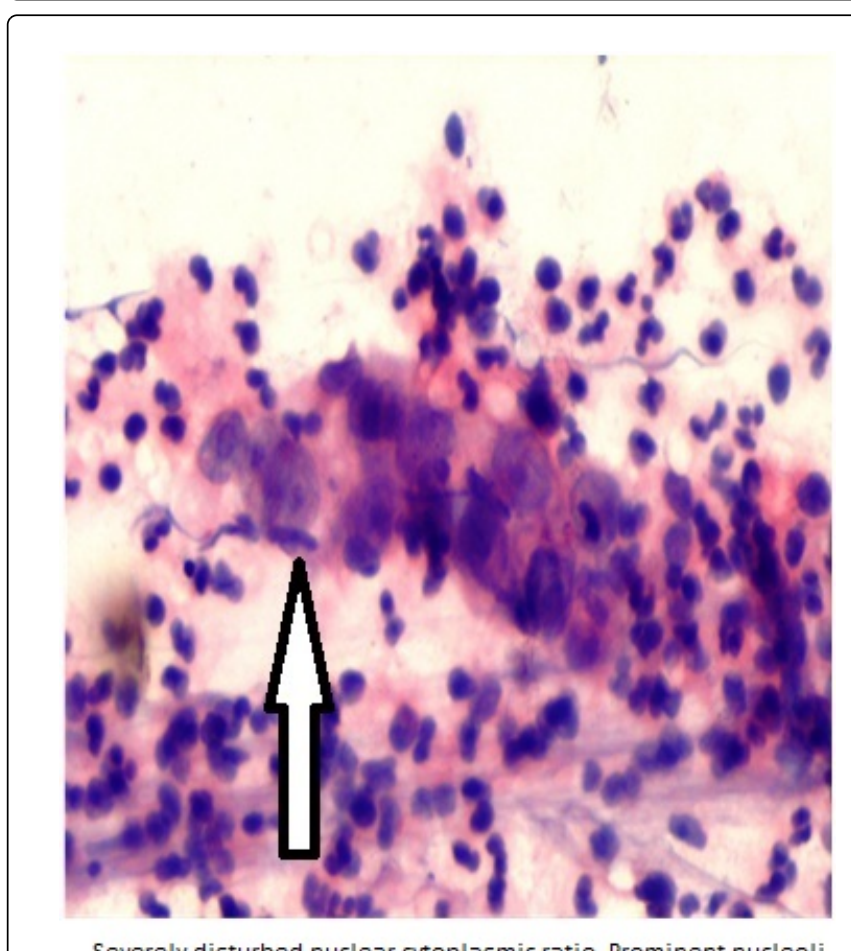

Figure 3: Severly disturbed nuclear cytoplasmic ratio. Prominent nuclei. 
Page 3 of 4

Table 1 shows the frequency association between the numbers of 'pan' consumed per day with the development of dysplasia. After checking homoscedasticity with F-test, 2-sample t-test was applied which showed that the proportion $(72.1 \%)$ of heavy 'pan' consumers developing oral mucosal dysplasia was significantly ( $p$ value $=0.001$ ) higher than the proportion (47.1\%) of light 'pan' consumers. Another important association was observed between the frequency of squamous epithelial dysplasia and the duration of pan chewing. In the group of subjects using pan for more than 10 years, the frequency of epithelial dysplasia was $79.6 \%$ as compared to $42.3 \%$ among the group of subjects using pan for less than 10 years. This difference was statistically significant ( $\mathrm{p}$ value $=0.0001$ ) when a 2 -sample $\mathrm{t}$-test was applied proceeded by F-test for homoscedasticity. Thus, H0 was rejected in the above mentioned scenario. The comparison between pans containing tobacco versus pan free of tobacco was done. The proportion $(45.2 \%)$ of subjects using tobacco containing pan was compared with the proportion $(33.3 \%)$ of subjects using tobacco free pan with a 2-sample t-test which showed no statistical difference of frequency of epithelial dysplasia between the two groups $(p=0.730)$ and $\mathrm{HO}$ was accepted in this case. So, pan was found as an independent risk factor of the development of phenotypic epithelial dysplasia.

\begin{tabular}{|l|l|l|l|}
\hline \multirow{2}{*}{ Parameters } & \multicolumn{2}{|l|}{ Epithelial dysplasia } & \multirow{2}{*}{ p value } \\
\cline { 2 - 3 } & Present & Absent & \\
\hline $\begin{array}{l}\text { Number of pans chewed per } \\
\text { day }\end{array}$ & $47.1 \%$ & $52.9 \%$ & \multirow{2}{*}{0.001} \\
$1-5(n=157)$ & $62.0 \%$ & $38.0 \%$ & \\
$6-10(n=100)$ & $72.1 \%$ & $27.9 \%$ & \\
$>10(n=43)$ & & & \\
\hline $\begin{array}{l}\text { Duration of pan chewing } \\
<10 \text { years ( } n=177) \\
\geq 10 \text { years }(n=123)\end{array}$ & $42.4 \%$ & $57.6 \%$ & 0.0001 \\
\hline $\begin{array}{l}\text { Type of pan } \\
\text { With tobacco }(n=115) \\
\text { Without tobacco }(=9)\end{array}$ & $79.7 \%$ & $20.3 \%$ & \\
\hline
\end{tabular}

Table 1: Associations between epithelial dysplasia and pan consumption

Correlation was determined between the severity (grades) of oral mucosal dysplasia and pan consumption using $\mathrm{r}(\mathrm{rho}=0)$ as null hypothesis. Grades of epithelial dysplasia were found to have significant positive correlation with number of pans consumed per day $(\mathrm{r}=0.184, \mathrm{p}=0.001)$ and duration of pan chewing $(\mathrm{r}=0.304, \mathrm{p}=0.0001)$ as shown in Table 2.

\section{Discussion}

In the present study, early morphological changes within buccal mucosa of habitual pan chewers have been described. A total of 300 habitual pan chewers with a male preponderance from Lahore City were included in the study, however, the dysplastic changes in mucosa were not affected by gender or other demographic features. Male preponderance was due to the fact that pan chewers were collected from various pan shops and due to religious and socio-cultural reasons, females avoid coming and buy pan at pan shops which are mostly run by males. Secondly, males are more commonly found to be pan chewers. Cytological features of epithelial cell dysplasia along with its grade were observed which were then related with various parameters of pan consumptions like number of pan consumed per day and total duration of pan chewing to determine the dose-response relationship between pan chewing and oral epithelial dysplasia.

\begin{tabular}{|l|l|l|}
\hline Variables & \multicolumn{2}{|l|}{ Grades of Epithelial Dysplasia } \\
\hline Duration of pan eating in years & Correlation Coefficient & $0.304^{* *}$ \\
\cline { 2 - 3 } & p value (2-tailed) & 0.0001 \\
\cline { 2 - 3 } & $\mathrm{N}$ & 300 \\
\hline Number of pan consumed per day & Correlation Coefficient & $0.184^{* *}$ \\
\cline { 2 - 3 } & p value (2-tailed) & 0.001 \\
\cline { 2 - 3 } & $\mathrm{N}$ & 300 \\
\hline
\end{tabular}

Table 2: Correlations between pan consumption and grades of epithelial dysplasia

Dysplastic change is reported to be the best forecaster of future malignancy, the more severe the dysplasia, the greater the likelihood of malignant transformation [11]. In current study, oral epithelial dysplasia was observed in $57.7 \%$ of the habitual pan chewers. Among them, mild $22 \%$, moderate $25 \%$ and $11 \%$ had severely dysplastic epithelial cells. Jaber et al. [12] conducted a study on large cohort of residents in Western Europe and reported that majority of the cases were mild or moderately dysplastic whereas severely dysplastic cases were uncommon. This was in coherence with the current study.

Pre-malignant lesions of oral cavity showed dysplastic cells characterized by nuclear enlargement with variation in size and shape of the cells and eosinophilic cytoplasm. Only a small percentage of cells showed severe dysplasia, characterized by perinuclear condensation of chromatin and abnormal mitosis [12]. Another study consisted of 250 individuals with a definite history of betel nut with smoking for duration of more than 5 years. Cytological mild dysplasia was seen in 4 whereas 2 cases showed moderate dysplasia. None of the cases showed severe dysplasia or malignant cells on cytology [13]. Tennakoon and Bartlett [14] observed that 14\% of betel chewers demonstrated epithelial cell dysplasia. In another study, Chen et al. [15] collected 80 specimens of buccal mucosa from betel quid chewers. Half of all these samples were identified with epithelial dysplasia. Among these samples, 20 showed the mild dysplasia and 20 samples moderate to severe dysplasia. In a retrospective case control cohort study, oral epithelial dysplasia was identified among $4 \%$ of the cases. Among these cases, only one case depicted moderate degree of dysplasia while the remaining three showed mild dysplasia [16].

A study from India found that the average number of pan consumed per day in that population was quite high i. e; 10-15 pans/ day and therefore, the risk of oral dysplasia and precancerous lesions was higher than general population [17]. Another study showed that those subjects who had consumed quid containing tobacco for more than 5 years were at a greater risk to develop dysplastic lesions as compared to those who were consuming it for less than 5 years [18]. A study from United States revealed that the use of habitual tobacco chewing is on the rise among its population. This practice therefore poses a threat of oral epithelial cell dysplasia and later on oral malignancy in susceptible individuals [19]. Wen and colleagues conducted a study that supported the findings of above mentioned studies that chewing betel quid induces local irritation and trauma in 
the oral mucosa, thus leading to chronic inflammation, oxidative stress, and cytokine production. The resultant traumatic wound therefore provides easier access to the system for carcinogens contained in betel quid [20]. They also found the genomic instability in betel quid chewers which could play a role in the malignant transformation of oral mucosa.

\section{Conclusions}

The study concludes that epithelial dysplasia was common among chronic pan chewers in Lahore city. Significant association and correlation was found between epithelial dysplasia and number of pans consumed per day as well as duration of pan consumption.

\section{Acknowledgements}

Authors are thankful to all the pan shopkeepers, administration of Mayo Hospital and University of Health Sciences and Mr. Sameer Anjum, Laboratory Technician at the Department of Morbid Anatomy and Histopathology, UHS Lahore.

\section{References}

1. Klieb HBE, Mackinins ML, Burgess KL (2010) Areca nut and oral health implications. Oral Health Journal 100:65-73.

2. Shah SMA, Merchant AT, Luby SP, Chotani RA (2002) Addicted school children prevalence and characteristics of areca nut chewers among primary school children in Karachi.J Paediatr Child Health38:507-510.

3. Zhang X, Reichart PA (2007)A review of betel quid chewing, oral cancer and precancer in Mainland China. Oral Oncol 43: 424-430.

4. Nair U, Bartsch H, Nair J (2004) Alert for an epidemic of oral cancer due to use of betel quid substitutes gutkha and pan masala: a review of agents and causative mechanisms. Mutagenesis 19: 251-262.

5. Mohan BC,Angadi PV (2013)Exfoliative Cytological Assessment of Apparently Normal Buccal Mucosa among Quid Chewers Using ArgyrophilicNucleolar Organizer Region Counts and Papanicolaou Staining. Actacytologica57:164-170.

6. Ghani WM, Razak IA, Yang YH, Talib NA, Ikeda N, Axell T, et al.( 2011) Factors affecting commencement and cessation of betel quid chewing behaviour in Malaysian adults. BMC public health11:82.

7. Reibel J (2003) Progression of oral premalignant lesions: significance of clinical, histopathological and molecular biological characteristics. Crit Rev Oral Biol Med 14: 47-62.
8. Scully C(2014) Challenges in predicting which oral mucosal potentially malignant disease will progress to neoplasia. Oral diseases 20:1-5.

9. Foy JP, BertolusC, William Jr WN, Saintigny P (2013) Oral Premalignancy: The Roles of Early Detection and Chemoprevention. Otolaryngologic Clinics of North America 46:579-597.

10. Speight PM (2007) Update on oral epithelial dysplasia and progression to cancer. Head Neck Patho11:61-66.

11. Ries J,Agaimy A,Vairaktaris E, Kwon Y,Neukam FW, Strassburg LH, Nkenke E, et al. (2012) Evaluation of MAGE-A expression and grade of dysplasia for predicting malignant progression of oral leukoplakia. International journal of oncology41: 1085-1093.

12. Jaber A, Porter SR, Speight P, Evesone JW (2003) Oral epithelial dysplasia: clinical characteristics of western European residents Oral Oncol39:589-596.

13. Radoi L, Luce D (2013) A review of risk factors for oral cavity cancer: the importance of a standardized case definition. Community dentistry and oral epidemiology 4: 97-109.

14. Tennakoon GE, Bartlett GC (1969) Effect of Betel chewing on the oral mucosa. Br J Cancer23:39-43.

15. Chen YK, Hsuen SS, Lin LM (2002) Increased expression of inducible nitric oxide synthase for human oral submucous fibrosis, verruc ous hyperplasia and verrucous carcinoma. Int $J$ Oral MaxillofacSurg31:419-422.

16. Abbas AM, Ahmed GA (2012) Assessment of oral epithelial proliferative markers among Sudanese Toombak dippers using conventional cytological methods. IJMMS1:1-19.

17. Misra V, Singh PA, Lal N, Agarwal P, Singh M, et al. (2009) Changing pattern of oral cavity lesions and personal habits over a decade : Hospital based Record Analysis from Allahabad. Indian J Community Med34:321-325.

18. Sajid K, Panwar, Shakeel M, Ansari, Shakila K, et al. (2012) Oral precancerous lesions in tobacco users attending dental outdoor in Jhalawar district of Rajasthan. Natl J community Med3:502-505.

19. Rubinstein I, Pedersen GW (2002) Bacillus species are present in chewing tobacco sold in the United States and evoke plasma exudation from the oral mucosa. ClinDiagn Lab Immunol9:1057-1060.

20. Wen CP, Tsai MK, Chung WS, Hsu HL, Chang YC, et al. (2010) Cancer risks from betel quid chewing beyond oral cancer : a multiple - site carcinogen when acting with smoking. Cancer Causes Control21:1427-1435. 